\title{
SISTEM INFORMASI LAYANAN BIMBINGAN BELAJAR BERBASIS WEB (STUDI KASUS : BIMBEL NABILA)
}

\author{
Abdul Hafid Alaudin ${ }^{1}$, Andy Prasetyo Utomo ${ }^{2}$, Supriyono ${ }^{3}$ \\ 1,2,3 Program Studi Sistem Informasi, Fakultas Teknik, Universitas Muria Kudus
}

\section{Article Info:}

Dikirim: 29 Juni 2021

Direvisi: 30 Juni 2021

Diterima: 30 Juni 2021

Tersedia Online: 30 Juni 2021

Penulis Korespondensi:

Abdul Hafid Alaudin

Universitas Muria Kudus,

Kudus, Indonesia

Email:

abdulhafidalaudin123@gmail.com

\begin{abstract}
Abstrak: Lembaga bimbingan belajar non formal di Kota Kudus sudah sangat banyak, salah satunya pada lembaga bimbingan belajar Nabila. Lembaga bimbingan belajar ini dikelola secara pribadi oleh Bapak Bijanto S.Pd yang berdiri sejak tanggal 20 Mei 2009. Lokasi dari Bimbel Nabila sendiri berada di Jl. Suryo kusumo No.1 (Depan Pasar Brayung) Desa Kesambi Kecamatan, Mejobo Kabupaten Kudus. Metode yang diterapkan pada bimbel nabila adalah metode tatap muka dengan pengkategorian bimbel secara kelompok terdiri dari 1 guru pengajar (tentor) dan kelompok belajar yang beranggotakan maksimal 12 orang siswa / siswi dan secara privat. Kendala yang ada pada bimbel Nabila antara lain: pendaftaranya masih bersifat secara langsung, penjadwalan sering terjadi permasalahan, metode pembelajaranya masih menggunakan media tatap muka, hambatan dalam pembelajaran secara tatap muka antara lain: dalam penyampaian materi, belum semua siswa memahami materi yang di sampaikan tutor, Dalam evaluasi materi juga masih belum efektif, Dalam pembahasan pekerjaan rumah siswa masih belum efektif. Berdasarkan masalah pada lembaga pendidikan non-formal Nabila maka diterapkan "Sistem Informasi Layanan Bimbingan Belajar Berbasis Web (Studi Kasus Bimbel Nabila)” dengan tujuan untuk mempermudah guru dan siswa dalam kegiatan belajar mengajar.
\end{abstract}

Kata kunci: sistem informasi; layanan: bimbel; web.

\begin{abstract}
There are many non-formal tutoring institutions in the Kudus City, one of which is the Nabila Bimbel tutoring institution. This tutoring institution is managed privately by Mr. Bijanto S.Pd, who was founded on May 20, 2009. The location of Bimbel Nabila itself is on Jl. Suryo kusumo No.1 (in front of Brayung Market) Kesambi Village, Mejobo, Kudus Regency. The method applied to tutoring is a face-to-face method with the categorization of tutoring in groups consisting of 1 teacher (tentor) and a study group consisting of a maximum of 12 students and private. The obstacles that exist in Nabila's tutoring include: the registration is still direct, scheduling problems often occur, the learning method still uses face-to-face media, obstacles in face-to-face learning include: in delivering material, not all students understand the material conveyed by the tutor, In evaluating the material it is still not effective. In discussing the homework of students, it is still not effective. Based on the problems at Nabila's non-formal educational institutions, the "Web-Based Tutoring Service Information System (Bimbel Nabila Case Study)" was implemented with the aim of making it easier for teachers and students in teaching and learning activities.
\end{abstract}

Keywords: information systems; services; tutoring; web. 


\section{PENDAHULUAN}

Pendidikan merupakan hal yang paling utama dalfiam kehidupan manusia membangun sebuah karakteristik anak terdapat pada lembaga pendidikan, oleh sebab itu media pembelajaran tidak hanya di dapat di sekolah-sekolah saja melainkan bisa di dapat di lembaga non formal seperti di lembaga bimbingan belajar.

Lembaga bimbingan belajar non formal di Kota Kudus sudah sangat banyak, salah satunya pada lembaga bimbingan belajar Nabila. Lembaga bimbingan belajar ini dikelola secara pribadi oleh Bapak Bijanto S.Pd yang berdiri sejak tanggal 20 Mei 2009. Lokasi dari Bimbel Nabila sendiri berada di Jl. Suryo kusumo No.1 (Depan Pasar Brayung) Desa Kesambi Kecamatan Mejobo, Kabupaten Kudus. Metode yang diterapkan pada bimbel nabila adalah metode tatap muka dengan pengkategorian bimbel secara kelompok terdiri dari 1 guru pengajar (tentor) dan kelompok belajar yang beranggotakan maksimal 12 orang siswa / siswi dan secara privat.

Sebelum siswa mengikuti bimbingan belajar, siswa diharuskan mengisi formulir pendaftaran yang meliputi data diri, asal sekolah, pilihan pelajaran dan kelas, serta guru sendiri mendaftarkan diri ke lembaga bimbingan belajar. Namun dalam tahapan ini masih bersifat langsung dengan siswa datang ke lokasi bimbingan belajar, kemudian menuliskan data diri, asal sekolah, pilihan pelajaran dan kelas secara tertulis. Hal ini sering terjadi permasalahan seperti formulir rusak atau robek, formulir hilang atau terselip sehingga menyulitkan perekapan data siswa dan data guru. Hal lain seperti penjadwalan sering terjadi perubahan jadwal tentor yang mendadak sehingga ini menyulitkan dan membingungkan bagi siswa. Selain itu metode pembelajarannya masih menggunakan media tatap muka yang mempertemukan 1 tentor dan 12 siswa setiap kelompoknya. Sehingga jika satu siswa ada yang tidak berangkat tentu

menyebabkan siswa tidak mendapatkan materi secara merata. Karakteristik siswa berbeda-beda ada siswa yang malu bertanya, ada yang acuh tak acuh dengan materi yang diberikan oleh tentor terhadap siswa dan ada juga yang aktif bertanya, jika siswa yang malu bertanya tentu ini akan membuat siswa jadi rugi atau ketinggalan materi. Selain itu, dalam pembelajaran secara tatap muka masih terdapat beberapa hambatan antara lain : dalam penyampaian materi belum semua siswa memahami materi yang di sampaikan tutor, dalam evaluasi materi juga masih belum efektif di akibatkan karena tidak memili waktu yang cukup setelah proses pembelajaran. Dalam pembahasan pekerjaan rumah siswa / pekerjaan rumah masih belum efektif di karenakan tidak memilik cukup waktu untuk pembahasan.

Kelebihan dari E learning yang saya buat pada sistem ini yaitu adanya fitur Kuis atau ruang latihan. Kuis atau ruang latihan berisi soal-soal materi pembelajaran mata pelajaran yang di dalamnya terdapat berbagai macam soal-soal yang di share oleh tutor dan dapat di buat latihan mengerjakan soal-soal materi pembelajaran. Kuis atau ruang latihan itu sendiri di gunakan untuk mengevaluasi proses pembelajaran siswa bimbingan belajar untuk mengetahui sejauh mana kemampuan siswa tersebut dalam menyerap materi yang telah di berikan oleh Tutor / guru. Selain itu, di dalam E-learning juga terdapat fitur Share materi yang di gunakan untuk mengupload materi oleh tutor kepada siswa agar siswa yang tidak masuk / terlambat dalam mengikuti bimbel dapat mendownload materi tersebut melalui E-learning. Selain itu, di dalam E-learning saya juga terdapat fitur yaitu Upload Video pembelajaran daring serta terkoneksi dengan youtube agar siswa agar lebih memahami dan memudahkan proses pembelajaran tersebut.

Berdasarkan masalah pada lembaga pendidikan non-formal Nabila maka diterapkan "Sistem Informasi Layanan Bimbingan Belajar Berbasis Web (Studi Kasus Bimbel Nabila)" dengan tujuan untuk mempermudah guru dan siswa dalam kegiatan belajar mengajar

\subsection{Rumusan Masalah}

Berdasarkan uraian latar belakang yang telah di atas, maka penulis merumuskan permaslahan diatas yaitu bagaimana cara merancang aplikasi Sistem Informasi Layanan Bimbingan Belajar Berbasis Web (Studi Kasus Bimbel Nabila). Sehingga dapat memudahkan kinerja pada pihak lembaga bimbel Nabila.

\subsection{Tujuan}

Tujuan dari penelitian yang dilakukan adalah sebagai berikut :

a. Membangun sistem informasi layanan bimbingan belajar berbasis web responsif pada lembaga bimbingan belajar Nabila.

b. Memberikan kemudahan kepada siswa untuk mengetahui sistem pendaftaran, penjadwalan, administrasi, absensi dan e learning / ruang latihan.

c. Memberikan kemudahan pada lembaga bimbingan belajar itu sendiri.

d. Memberikan kemudahan siswa dan lembaga bimbingan belajar saat bertransaksi dalam proses pembayaran.

e. Mempermudah layanan informasi bagi pihak orang tua siswa dalam pemilihan kelas.

f. Memberikan kemudahan pada tutor / guru dalam memberikan materi pembelajaran

\subsection{Tinjauan Pustaka}

Pada Jurnal yang di tulis oleh Diana Laily Fithri, Andy Prasetyo Utomo dan Fajar Nugraha (2020) yang berjudul " Penerapan Aplikasi Cloud E-Learning Di SMA PGRI Kudus" Dari hasil pelaksanan pengabdian yang telah dilakukan menunjukkan bahwa teknologi cloud computing yang diterapkan kepada aplikasi elearning dapat membantu kegiatan 
pembelajaran di SMA PGRI Kudus. Selain itu dengan menggunakan teknologi cloud computing yang mempunyai karakteristik "resource sharing" beberapa SMA dapat sekaligus menggunakan sebuah aplikasi elearning di sebuah server yang sama, sehingga dapat menghemat sumber daya dan biaya operasional, pengelolaan dan perawatan aplikasi.[1]

Pada Jurnal yang di tulis oleh James Surya Seputro dan Henny Hartono (2019) yang berjudul" Perancangan Sistem Informasi Akademik Berbasis Android (Studi Kasus: Bimbingan Belajar Blessing)" Hasil penelitian perancangan aplikasi sistem informasi akademik berbasis mobile pada lembaga belajar Blessing. dalam Perancangan sistem informasi akademik berfokus untuk menyediakan materi pembelajaran dan mengakomodasi proses belajar secara online serta menyediakan fitur pendukung lain seperti administrasi, penjadwalan, percakapan, dan absensi khusus untuk lembaga belajar Blessing agar memberikan kemudahan saat melakukan kegiatan pembelajaran dan penyimpanan berkas - berkas file yang lebih terpusat. selain itu, Sistem informasi akademik yang diterapkan pada lembaga belajar Blessing akan memenuhi kebutuhan dalam memberikan pelayanan yang lebih baik dikarenakan kecepatan dan keakuratan informasi yang disimpan di dalam sistem berbasis mobile yang mendukung proses pembelajaran secara lebih fleksibel dibandingkan metode pembelajaran konvensional karena dapat diakses dimana dan kapan saja sehingga membantu pengelolaan kebutuhan pembelajaran. Perancangan sistem informasi akademik berbasis android dengan mobile application development life cycle (MADLC) merupakan standar dalam mengembangkan aplikasi berbasis mobile karena model MADLC mendukung alat perangkat keras dan fitur - fitur pada aplikasi mobile. Secara lebih spesifik perancangan sistem perlu memperhatikan beberapa spesifikasi dan syarat dalam mengembangkan aplikasi mobile seperti sistem operasi, tipe perangkat keras, tampilan antarmuka grafis, karakteristik dan ukuran aplikasi, serta lingkungan operasional tempat menggunakan aplikasi. [2]

Pada Jurnal yang di tulis oleh Fitri Ayu dan Wahyuni Sholeha (2019) yang berjudul "Rancang Bangun Sistem Informasi Penjadwalan Mata Pelajaran Berbasis Web Pada Smart Center Pekanbaru" Dengan telah terselesaikannya seluruh kegiatan penelitian, analisa sistem, perancangan program sampai dengan implementasi dan pembahasan. Maka Sistem baru ini dapat membuat proses pembuatan dan pengelolaan jadwal mata pelajaran pada Smart Center Pekanbaru lebih efektif dan efisien. selain itu, Dengan adanya sistem informasi yang terkomputerisasi, dapat mengurangi resiko terjadinya kekeliruan / kesalahan dalam pengelolaan data jadwal matapelajaran dan Dengan dibangunnya sistem informasi ini, dapat memudahkan admin dalam melakukan pekerjaanya dan dapat menyajikan informasi secara cepat, tepat dan akurat. [3]

Pada jurnal yang ditulis oleh Miwan Kurniawan Hidayat dan Siti Fatimah Fatmawati (2020) yang berjudul "Rancang Bangun Sistem Informasi Akademik Bimbingan Belajar (SIBIJAR)" dari hasil penelitian mengenai merancang dan membangun sistem informasi pada bidang akademik lembaga bimbingan belajar. Sistem informasi lembaga bimbingan belajar yang dirancang dan dibangun sudah sesuai dengan prosedur yang berjalan. Dengan Melalui penggunaan sistem informasi lembaga bimbingan belajar ini telah mengubah cara pengarsipan data secara sistem manual menjadi terkomputerisasi dan menghindari faktor kesalahan dalam pengolahan data dan informasi. Pada penggunaan sistem informasi lembaga bimbingan belajar dapat memberikan kemudahan dalam penginputan data, proses transaksi, pelaporan serta dapat menghasilkan informasi untuk umum, siswa, tentor dan admin secara tepat guna. [4]

\section{METODOLOGI PENELITIAN}

Metode yang dipergunakan didalam penelitian Sistem Informasi Layanan Bimbingan Belajar Berbasis Web (Studi Kasus : Bimbel Nabila) menggunakan UML berbasis Web ini menggunakan kajian (research) terhadap model pengembangan yang sudah ada selanjutnya berdasarkan hasil kajian tersebut dirumuskan analisis dan desain e-learning. Penelitian ini menggunakan tahapan-tahapan sebagai berikut :

\subsection{Perancangan Penelitian}

Perancangan penelitian dilakukan di ldengan menggunakan aplikasi perancangan UML

\subsection{Pengumpulan Data}

Untuk memperoleh data yang tepat dan akurat maka metode pengumpulan data dilaksanakan dengan cara :

a. Observasi

Merupakan metode pengamatan dan pencatatan dari permasalahan yang ditemui, Bimbingan Belajar Nabila.

b. Interview

Metode interview adalah tahapan pengumpulan data melalui tanya jawab langsung dengan Bimbingan Belajar Nabila, yang berkaitan dengan tujuan penelitian.

c. Studi Pustaka

Untuk memperoleh teori yang sesuai dan dapat digunakan sebagai landasan teori dan kerangka dalam penelitian dengan tema e-commerce, maka diperlukan jurnal penelitian dengan bahasan mengenai elearning, jurnal penelitian dengan bahasan industri, jurnal penelitian dengan bahasan pengembangan sistem. Sedangkan untuk mendapatkan metodologi yang sesuai maka perlu membandingkan antara teori dengan fakta yang terjadi di lapangan. 


\subsection{Analisa Kebtuhan Sistem}

Tahapan analisa terhadap kebutuhan dari Rancang Bangun E-learning Pada Bimbingan Belajar Nabila adalah sebagai berikut:

a. Identifikasi keberadaan Bimbingan Belajar Nabila dilakukan melalui observasi dan interview dengan pemilik.

b. Analisis dan identifikasi kebutuhan sistem informasi untuk memperoleh generating sistem analysis, problem analysis dan requirements analysis.

c. Perancangan Model e-commerce Bimbingan Belajar Nabila yang dilakukan dengan membuat database design, conceptual design dan design detail.

\subsection{Desain Sistem}

Pada tahap ini dilakukan penyusun desain rancang bangun e-learning pada Bimbingan Belajar Nabila.Setelah mendapatkan data dan analisa kebutuhan maka dilanjutkan dengan tahap disain dimana yng didisain diantaranya adalah:

a. Melakukan disain database

b. Melakukan disain antar muka disesuaikan dengan kebutuhan pengguna

c. Merealisasi disain dan pengkodean sesuai dengan perancangan

\subsection{Implementasi Sistem}

Pada tahap ini merupakan tahap implementasi dimana proses implementasi adalah melakukan penginstalan aplikasi kedalam komputer yang nantinya akan digunakan untuk e-learning di Lembaga BImbel Nabila.

\subsection{Pengujian Sistem}

Tahap pengujian terhadap software e-learning yang sudah dibangun. Pengujian dilakukan dengan metode black box dengan menguji fungsionalitas dari setiap fungsi disemua halaman aplikasi dimana akan diuji efektifitas penggunaan software tersebut dalam menangani pemesanan menu makanan dan booking.

\section{HASIL DAN PEMBAHASAN}

Berdasarkan analisa yang diperoleh dari lapangan maka hasil dari proses bisnis pada Bimbingan Belajar Nabila adalah sebagai berikut:

Tabel 1. Proses business use case

\begin{tabular}{|c|c|c|c|}
\hline No & Proses Bisnis & Aktor & Business Use Case \\
\hline 1. & Admin memberikan formulir pendaftaran & Admin & Memberikan formulir pendaftaran \\
\hline 2. & Siswa mengisi formulir pendaftaran & Siswa & Mengisi formulir pendaftaran \\
\hline 3. & $\begin{array}{l}\text { Admin mengecek kelengkapan data pendaftaran } \\
\text { yang telah diisi siswa }\end{array}$ & Admin & Melihat kelengkapan \\
\hline 4. & Siswa melengkapi formulir yang masih kurang & Siswa & Melengkapi formulir \\
\hline 5. & $\begin{array}{l}\text { Admin menyimpan berkas formulir pendaftaran } \\
\text { yang telah lengkap }\end{array}$ & Admin & Menyimpan berkas \\
\hline 6. & $\begin{array}{l}\text { Admin memberikan pengarahan tentang } \\
\text { pembayaran }\end{array}$ & Admin & Memberikan pengarahan \\
\hline 7. & Siswa membayar bimbel sesuai pilihan & siswa & Membayar bimbel \\
\hline 8. & $\begin{array}{l}\text { Siswa membayar bimbel dengan melakukan } \\
\text { transfer }\end{array}$ & Siswa & Transfer \\
\hline 9. & $\begin{array}{l}\text { Siswa membayar bimbel langsung tunai kepada } \\
\text { admin }\end{array}$ & Siswa & Membayar \\
\hline 10. & $\begin{array}{l}\text { Admin membuat kwitansi sebagai bukti } \\
\text { pembayaran }\end{array}$ & Admin & Membuat kwitansi \\
\hline 11. & $\begin{array}{l}\text { Admin mencatat bukti/kwitansi pembayaran } \\
\text { yang telah diterima dari siswa }\end{array}$ & Admin & $\begin{array}{l}\text { Mencatat bukti/kwitansi } \\
\text { pembayaran }\end{array}$ \\
\hline 12. & $\begin{array}{l}\text { Admin membuat laporan pendaftaran dan } \\
\text { pembayaran untuk diberikan kepada pengelola }\end{array}$ & Admin & $\begin{array}{l}\text { Membuat laporan pendaftaran dan } \\
\text { pembayaran }\end{array}$ \\
\hline 13. & $\begin{array}{l}\text { Pengelola melihat laporan pendaftaran dan } \\
\text { pembayaran untuk diarsipkan }\end{array}$ & Pengelola & $\begin{array}{l}\text { Melihat laporan pendaftaran dan } \\
\text { pembayaran }\end{array}$ \\
\hline 14. & $\begin{array}{l}\text { Admin menyusun jadwal bimbel untuk } \\
\text { diberikan kepada tentor dan siswa }\end{array}$ & Admin & Menyusun jadwal bimbel \\
\hline
\end{tabular}




\begin{tabular}{|c|c|c|c|}
\hline No & Proses Bisnis & Aktor & Business Use Case \\
\hline 15. & Tentor melakukan absensi kehadiran mengajar & Tentor & Melakukan absensi \\
\hline 16. & $\begin{array}{l}\text { Tentor melakukan konfirmasi ganti hari jika } \\
\text { berhalangan hadir pada jadwal yang telah } \\
\text { ditentukan }\end{array}$ & Tentor & Konfirmasi ganti hari \\
\hline 17. & Tentor melakukan konfirmasi terlambat & Tentor & Konfirmasi terlambat \\
\hline 18. & $\begin{array}{l}\text { Tentor melakukan konfirmasi rubah jam jika } \\
\text { jadwal diganti }\end{array}$ & Tentor & Konfirmasi rubah jam \\
\hline 19. & $\begin{array}{l}\text { Tentor memberikan materi dan daftar hadir } \\
\text { kepada siswa }\end{array}$ & Tentor & $\begin{array}{l}\text { Memberikan materi dan daftar } \\
\text { hadir }\end{array}$ \\
\hline 20. & Siswa mengisi daftar hadir & Siswa & Mengisi daftar hadir \\
\hline 21. & Admin membuat laporan kehadiran & Admin & Membuat laporan kehadiran \\
\hline 22. & Pengelola melihat laporan kehadiran & Pengelola & Melihat laporan kehadiran \\
\hline
\end{tabular}

\subsection{Diagram Use Case}

Diagram Use Case dari Sistem Informasi Layanan Bimbingan Belajar Berbasis Web ditunjukkan pada gambar 1.

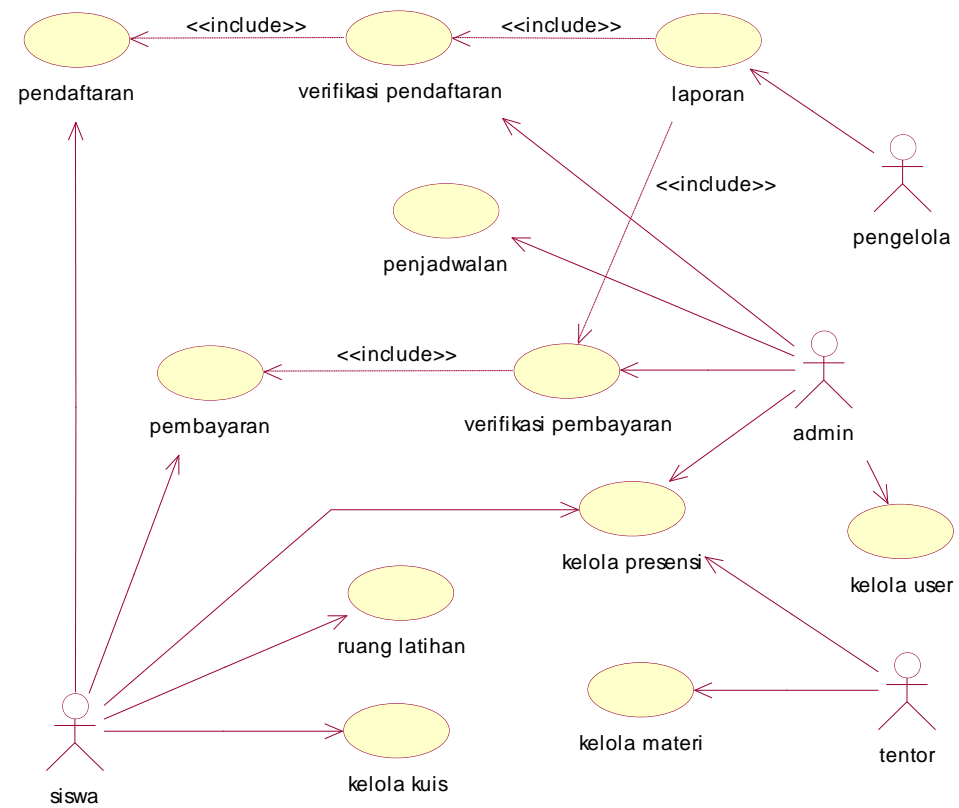

Gambar 1. Diagram Use Case Sistem Informasi Layanan Bimbingan Belajar Berbasis Web

\subsection{Tampilan Aplikasi}

Aplikasi berbasis web yang dihasilkan sudah bisa dijalankan dengan tampilan Dashboard utamanya ditunjukkan pada gambar 2 dan halaman dashboard bagi siswa ditunjukkan pada gambar 3 .

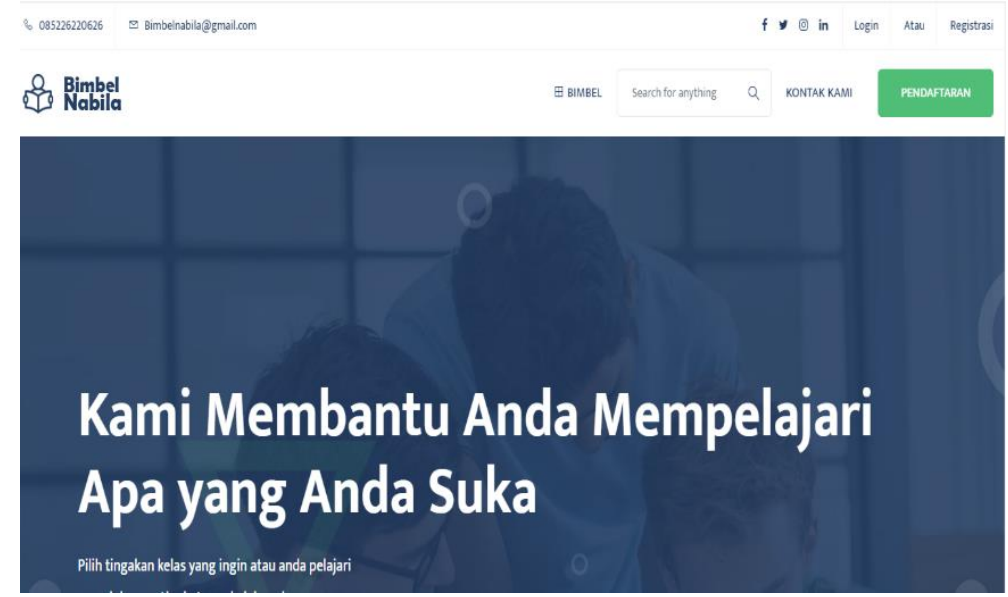

Gambar 2. Halaman Dashboard Utama 


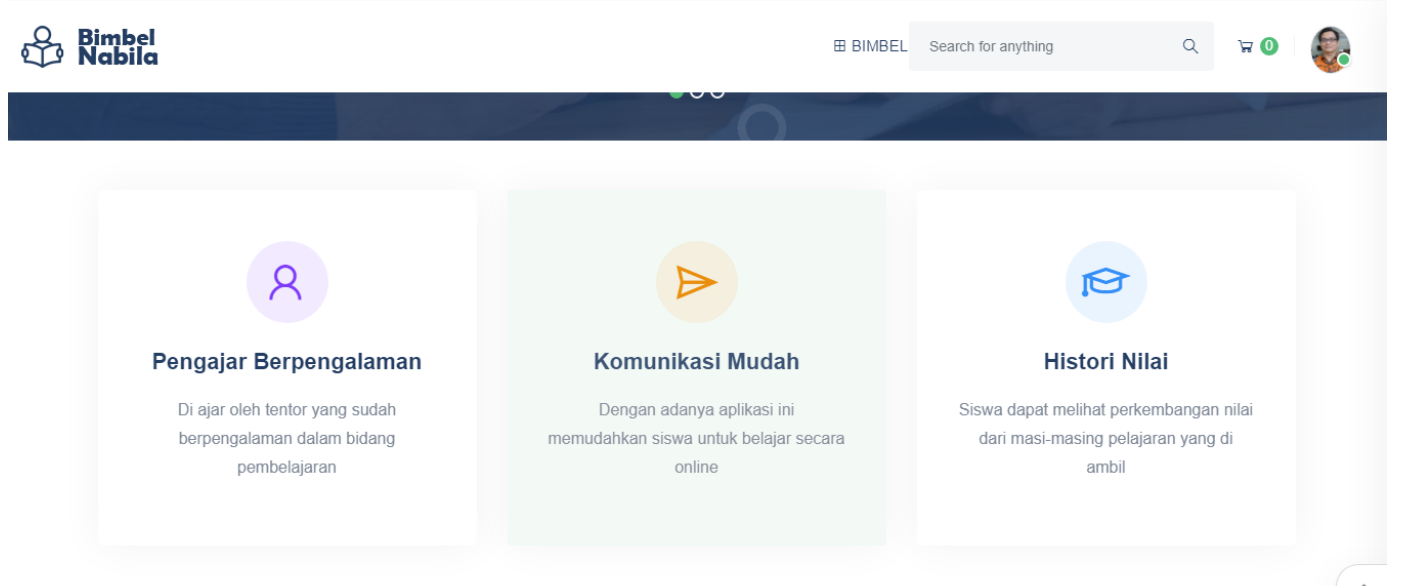

Gambar 6. Halaman Dashboard Siswa

\section{KESIMPULAN}

Dari hasil pengamatan, analisa dan proses perancangan sistem ketika penulis melakukan penelitian skripsi dapat disimpulkan bahwa:

1) Penelitian ini menghasilkan sebuah sistem bimbingan belajar untuk bimbel nabila

2) Sistem ini telah memberikan gagasan mengatasi permasalahan dalam proses mengelola bimbel Nabila mlai dari penngelola, admin, tentor da juga para siswa yang ada

3) Sistem ini akan menghitung skor yang didapat dalam proses pemberian kuis dan tentor, admin serta pengelola dapat mengecek seluruh data dan kegiatan yang di perlukan pada sistem..

\section{DAFTAR PUSTAKA}

[1] Nugraha, F., Utomo P. A., Fihtri L. D. (2020). Penerapan aplikasi cloud e-learning di SMA PGRI Kudus. 02(01), 1-8.

[2] Hartono, S. S. J. \& H. (2019). Perancangan Sistem Informasi Akademik Berbasis Android (Studi Kasus : Bimbingan Belajar Blessing). 4(2502).

[3] Intra-tech, J., Ayu, F., Sholeha, W., \& Informatika, M. (2019). Rancang bangun sistem informasi penjadwalan mata pelajaran berbasis web pada smart center pekanbaru. 3(1).

[4] Hidayat, M. K., \& Fatmawati, S. F. (2020). Rancang Bangun Sistem Informasi Akademik Bimbingan Belajar (SIBIJAR). J I M P - Jurnal Informatika Merdeka Pasuruan, 4(3), 12-17. 